\title{
Somos realmente livres? Contribuições de Santo Agostinho para nossa compreensão sobre a liberdade
}

Marco Antônio G. Bonelli'

Num livro bastante provocativo, A. T. Queiruga recorda algumas tragédias humanas do século $\mathrm{XX}$, como as experiências de humilhação, sofrimento e morte vivenciadas nos campos de concentração nazistas e pergunta sem rodeios: "É possível rezar depois de Auschwitz? É possível crer em Deus perante o panorama que nos esmaga com guerras e genocídios, com crimes e terrorismo, com fome e exploração, com dor, doença e morte?"2 Como é fácil notar, perguntas muito complexas não devem ser respondidas de maneira muito simples. O problema do mal se apresenta como questão inevitável, desafiadora e talvez até "insolucionável" a todos nós.

O problema não é apenas teológico, no sentido de propor as perguntas sobre a fé, e verificar se ainda é ou não possível crer em Deus no século XXI. O problema é também antropológico, provocando a pergunta direta que atinge e abala a todos nós. Diante do mal e do sofrimento humano tão presente em nossa vida pessoal e coletiva, existe mesmo a liberdade? Quem poderá imaginar-se livre diante da doença incurável, do crime impune, da violência mortal, dos desastres ecológicos, de sistemas econômicos e políticos que geram tanta miséria humana e exclusão social? O questionamento é, não apenas oportuno, como também necessário. Qualquer um que queira pensar em profundidade sua própria existência nesse mundo, terá que se defrontar com esta questão.

Santo Agostinho foi em sua época, provavelmente o grande protagonista do debate filosófico e teológico sobre a questão da liberdade e da libertação do ser humano no enfrentamento com o mal. Desde já é preciso dizer, não, ele não resolveu teoricamente todos os problemas relativos ao tema. O problema é tão humano e tão inevitável que continua vivo até hoje. Mas dentro do ambiente cultural dos séculos IV e V dC., suas reflexões foram tão vigorosas e conquistaram tanta repercussão,

\footnotetext{
1 Teólogo e Professor da Cultura Religiosa da PUC - Rio.

${ }^{2}$ QUEIRUGA A. T., Um Deus para hoje, São Paulo: Paulus, 1998, p. 17.
} 
que influenciaram imensamente o pensamento e a cultura ocidentais até hoje. Levando em consideração alguns temas e pensamentos agostinianos podemos encontrar inspirações para compreender e viver a liberdade neste conturbado século XXI. Eis o nosso desafio neste artigo.

\section{1 - Desejo que vem do íntimo do próprio ser humano}

Pedindo a licença poética ao leitor, gostaria de recorrer à arte da literatura para iniciarmos a conversa. No célebre "Romance XXIV ou da Bandeira da Inconfidência", Cecília Meireles nos diz o seguinte: "Ó vitórias, festas, flores, das lutas da independência! Liberdade - essa palavra, que o sonho humano alimenta: que não há ninguém que explique e ninguém que não entenda!". Nestes versos, a notável escritora brasileira nos mostra que a liberdade corresponde a um desejo humano muito profundo, por conter em si um anseio de vida, de justiça, autonomia pessoal, independência, soberania política, etc. Tantos significados e situações da vida humana expressos em uma única palavra! Trata-se de uma experiência humana difícil de ser definida conceitualmente, mas paradoxalmente muito evidente: todo mundo entende! Qualquer pessoa pode descobrir, compreender e viver a liberdade!

Em sintonia com essa percepção da busca humana por uma vida livre, santo Agostinho escreveu sobre o assunto, por ter experimentado intensamente o problema em sua própria vida pessoal. Aderiu a várias correntes filosóficas de seu tempo em sua "busca pela verdade" e isso o levou a formular alguns princípios teóricos sobre a existência do ser humano em geral. Iniciando ainda jovem essa busca desenfreada por viver e compreender a vida, ele gostou dos escritos do filósofo Cícero, aderiu aos conceitos filosóficos do maniqueísmo, encantou-se com novas versões do pensamento de Platão, (o chamado "neoplatonismo"), até conseguir, no aprofundamento de sua fé cristã, uma síntese satisfatória que "arrumasse as ideias" em sua cabeça e em seu coração.

Um primeiro aspecto que Agostinho percebeu foi que a liberdade está relacionada com essa busca de vida. Não é apenas a satisfação de poder agir como quiser. Ser livre é um aprendizado, uma conquista e frequentemente tem um quê de agitação interior, de procura e de "inquietude". Todos somos afetados pelos variados desafios do tempo presente. Podemos dizer que esta é uma característica humana muito 
básica. É frequente em todos nós essa sensação de "desequilíbrio" interior, de insatisfação, de sentir no próprio coração o eco de "perguntas sem resposta".

Essa inquietude foi um traço característico do pensamento e da vida de santo Agostinho. Foi para ele (será que não é também para nós?) uma "procura de si mesmo e em si mesmo" que nunca tem fim. Essa experiência tão humana e tal pessoal, da "busca da verdade sobre sua própria vida", levou Agostinho a entender que este era um caminho de "abertura ao infinito", uma sede interminável de futuro. Ele percebeu que o entendimento humano, sempre finito e limitado, deixa sempre espaço para que possamos perguntar: "Que mais?" Podemos saber mais? Algo mais podemos esperar dessa vida que estamos vivendo? O presente é sempre necessário, mas também sempre incerto, insuficiente e aberto a novos desenvolvimentos.

Esse foi um dos motivos que levou santo Agostinho a postular racionalmente a legitimidade da fé. Não se trata de acreditar em qualquer fantasia ou divagação religiosa ingênua, mas sim de compreender que só o próprio Infinito pode saciar essa sede infinita de autoconhecimento e felicidade que habita o ser humano. Referindo-se a Deus, como destino natural desse desejo humano de realização pessoal sem barreiras ou limites, Agostinho disse:

"Grande és tu, Senhor, e sumamente louvável; grande é a tua força, a tua sabedoria não tem limites! (...) Ora, o homem, (...) carregado com sua condição mortal, carregado com o testemunho do seu pecado (...) Ainda assim, quer louvar-te o homem, esta parcela de tua criação! Tu próprio o incitas para que sinta prazer em louvar-te. Fizeste-nos para ti e inquieto está nosso coração, enquanto não repousa em ti." 3

É bonito ver a consciência que Agostinho formou sobre a nossa condição humana. Penosa descoberta essa que fazemos: o ser humano "aposta" sua própria vida enquanto busca compreendê-la e tenta encontrar a verdade sobre si próprio. Vamos formando compreensões parciais e, no entanto, nenhuma delas pode oferecer uma reposta completa e plenamente satisfatória a esta sede de vida que habita o homem. No fundo, essa busca da verdade representa o "desejo de ser e estar inteiro" nas diversas etapas e experiências que passamos na vida.

\footnotetext{
${ }^{3}$ Santo Agostinho, Confissões 1, 1, 1.
} 
Desejo de sermos plenamente nós mesmos; necessidade de ser aquele "ser humano integrado" que almejamos ser.

Isso é um eminente anseio de ser livre, é um autêntico desejo de aprofundar a vivência de nossa própria liberdade. Neste sentido, a necessidade de vencer a ignorância sobre nós mesmos e ampliar nosso autoconhecimento, a vontade de superar a existência dispersa e fragmentada que levamos quando nos perdemos na multidão de tarefas do dia a dia...tudo isso expressa uma aspiração muito justa do ser humano: o desejo de uma vida plena e mais autêntica, em que nós possamos nos reconhecer.

Ao afirmar que um Mistério de Amor sem medida nos toca e impulsiona a seguir nessa busca, santo Agostinho nos deu uma dica poderosa, da direção em que essa mesma busca será mais proveitosa e satisfatória. Seguindo a "inquietude" do nosso próprio coração poderemos descobrir que nossas infinitas buscas revelam o anseio por uma vida mais autêntica, uma existência mais humana, uma vida mais livre...que só o Autor da Vida pode conceder.

Mas essa atitude sugerida por Agostinho ainda não resolve tudo. Como conceber e viver essa vida tão autêntica, tão humana e infinita, se constatamos cotidianamente a realidade dolorosa do mal e do sofrimento? A experiência da vida concreta no chão da história humana é sempre bastante limitada e ambígua. Que fazer?

2. Uma interminável busca de vida, em contextos sociais limitadores

Queremos ser felizes, justos, fraternos, mas nem sempre o resultado de nossas ações confirma nossas intenções. Habitualmente consideramos normal desejar saúde e paz para nós mesmos e para as pessoas em geral. No entanto, experimentamos igualmente a frustração desses desejos quando assumimos estilos de vida doentios, estressantes, marcados pelos imperativos da sobrevivência, do mercado de trabalho e por condições sociais e escolhas pessoais, que frequentemente "nos empurram" na direção contrária.

No expressivo e famoso texto de $\mathrm{Rm} 7,19$, São Paulo nos recorda esta situação tão familiar a todos nós. Racionalmente queremos o bem, mas ao mesmo tempo somos muito afetados pelo mal que nós mesmos praticamos. Desejemos naturalmente ser livres, no entanto sentimo-nos 
com frequência "escravos" de situações indesejadas, atados a contextos sociais muito diferentes do bem e da felicidade originalmente desejados. Estranha criatura é homem. Somos seres estruturalmente ambíguos: habitados por uma sede infinita de vida e simultaneamente marcados por tantos sinais de morte.

O curioso é que santo Agostinho, mesmo reconhecendo estas contradições, continua afirmando a existência da liberdade humana. É verdade que a vontade humana é vulnerável. Pode se tornar egoísta, interesseira, perversa, criminosa, imoral, etc. Isso corresponde àquela situação humana que o Cristianismo tradicionalmente classifica como "pecado". Mas mesmo nessa direção negativa, há uma dimensão de escolha e de ação que recai sobre o próprio ser humano.

Certa ocasião Santo Agostinho escreveu: "Deus me criou com o livre arbítrio: se tenho pecado, fui eu que pequei... não o fato, não a fortuna, não o diabo..." 4 . Esta é uma das muitas ocasiões em que nosso autor reconhece, mesmo nas más ações, o exercício de nossa liberdade. Dois aspectos sobressaem da análise de Agostinho sobre esta situação. Primeiro: algo deu errado no exercício da liberdade de escolha e decisão do ser humano. As escolhas deveriam vislumbrar atos justos e decisões inteligentes, tendo em vista a felicidade pessoal e o bem comum. Mas isto nem sempre ocorre. Em nossas ações pessoais, somos profundamente afetados e condicionados pelo contexto social conturbado em que vivemos. Segundo: $O$ ser humano precisa entender esta fragilidade que o caracteriza. Deve ser capaz de reconhecer quando erra, procurando reparar os sofrimentos resultantes de suas más ações. Ou seja, mesmo quando pecamos ou agimos mal, há a possibilidade e até o dever de assumir a responsabilidade por nossas escolhas.

Disso tudo se conclui que devemos aprender a direcionar ou reordenar a nossa capacidade de agir. Agostinho pressupõe que o livre arbítrio foi originalmente uma dádiva, uma capacidade natural que todos temos de raciocinar, avaliar, e decidir como agir em nossas vidas. Se utilizamos mal o dom do livre arbítrio dado por Deus isso é uma outra questão. Considerado em si mesmo, o livre arbítrio age como uma "dobradiça", um recurso "intermediário", que pode tanto voltar-se para o bem como para o mal. Cabe a nós desenvolver essa capacidade de escolha e ação.

\footnotetext{
${ }^{4}$ Santo Agostinho, Comentário aos Salmos 31, 2, 16.
} 
Em sentido positivo, o livre arbítrio não foi dado por Deus "para que" o homem pecasse. A finalidade natural do livre arbítrio é possibilitar que o homem possa, por sua própria vontade, optar pelo bem, pois somente assim ele poderá ser feliz. Em última instância, o objetivo de Deus ao conceder o livre arbítrio é a própria felicidade do ser humano. Mas, para tanto, o próprio ser humano precisa querer ser feliz, necessita pelo exercício da liberdade, "mover sua vontade" na direção certa. Por isso, o homem deve "amar essa boa vontade" que se orienta para o bem. Ele deve procurá-la e sustenta-la com afinco, pois é através do livre arbítrio, no empenho decidido da própria vontade, que o ser humano poderá alcançar "uma vida louvável e feliz" ${ }^{5}$

Assim notamos que Agostinho traça um caminho bastante realista, para pensarmos sobre a liberdade humana. Ela é um dom de Deus para o homem mas, ao mesmo tempo, se configura como uma experiência de enfrentamento das situações concretas da vida cotidiana. Em sua busca sincera de vida feliz, o ser humano experimenta sua própria liberdade como um impulso de vida que vai abrindo caminho no interior de contextos (políticos, econômicos, culturais, etc.) , que trazem inevitavelmente a marca do mal, da dor, do sofrimento e da morte. Esse mundo social e humano afetado pelo pecado condiciona e limita a capacidade de ação do homem, mas ainda assim, não anula aquela inquietude e aquela sede de vida que nos impulsionam a tentar organizar, da melhor maneira possível, nossa própria existência.

\section{A liberdade como vida nova, dinamizada pelo amor}

Se, como vimos, o contexto de nossas relações sociais é tão ambíguo e limitador, o que poderia sustentar de modo definitivo a liberdade humana? Baseado em sua própria história pessoal e na leitura dos textos bíblicos, Agostinho apresenta o amor como resposta mais profunda para os nossos questionamentos sobre a liberdade.

De fato, a experiência de ter se sentido amado por Deus gerou consequências imensas na vida de Agostinho. A sua conversão à fé cristã, sua crescente familiaridade com leituras e reflexões sobre os textos bíblicos produziram um aprofundamento notável, tanto em sua vida espiritual, como em sua produção teológica. Com efeito, depois dessas

\footnotetext{
5 Santo Agostinho, O livre arbítrio, 1, 13,28.
} 
mudanças, ele escreveu muitos livros, a fim de dar fundamentação e explicação teórica para os principais temas da fé cristã.

Alguns textos bíblicos the foram especialmente úteis, consolidando ideias e sentimentos profundos que Agostinho vinha estudando desde muito antes, acerca da condição humana. "Amemo-nos uns aos outros, pois o amor vem de Deus e todo aquele que ama nasceu de Deus e conhece a Deus (...) porque Deus é amor" (1Jo 4,7-8); "E a esperança não decepciona, porque o amor de Deus foi derramado em nossos corações pelo Espírito Santo que nos foi dado" (Rm 5,5) . Estes são apenas dois exemplos de textos bíblicos que foram muito apreciados por Agostinho como fonte de inspiração.

Ele percebeu que conseguiu redirecionar sua própria vida, a partir dessa convicção de fé muito íntima de que é possível e vale a pena mudar e "acreditar no amor". Assim, o amor é dom de Deus (Rm 5,5); é a força que move o ser humano à prática do bem $(\mathrm{Gl} 5,6)$ e que possibilita o pleno cumprimento dos mandamentos divinos ( $\mathrm{Rm}$ 13,9-10); consequentemente, o amor é o meio pelo qual se dá a vivência da justiça (Mt 22, 37-40). Ao meditar sobre estes e outros textos da Bíblia, Agostinho indica essa experiência do amor de Deus como caminho de salvação, ou seja, como meio concreto de viver o bem superando o mal. Nesta perpectiva é que nosso autor escreve:

“(...) o Senhor, abreviando e resumindo sua palavra sobre a terra (Is 10,23; Rm 9,28) afirmou que toda a Lei e os Profetas dependem de dois preceitos. (...) 'Amarás o Senhor teu Deus de todo o teu coração, de toda a tua alma e de todo o teu entendimento; e amarás o teu próximo como a ti mesmo' (Mt 22, 37-40). Não é verdade que o cumpridor destes mandamentos cumpre toda a justiça?" 6

Nota-se que Agostinho defende aqui, a convicção de que ser livre não é ter permissão para praticar o mal. Ao contrário, ele enfatiza que a verdadeira liberdade consiste em praticar a justiça desejada e proposta por Deus. Ou seja, nossas relações humanas e sociais somente serão autenticamente livres se forem dinamizadas pelo amor a Deus e ao próximo. Isso não significa que a questão do mal e do sofrimento humano se resolve com um "olhar ingênuo e idealizado" sobre a realidade. O heroísmo tolo e o idealismo puramente retórico não são capazes de

\footnotetext{
${ }^{6}$ Santo Agostinho, O Espírito e a Letra 36,64.
} 
alterar a realidade social tão desumana, que aflige e maltrata tantos milhões de pessoas no Brasil e no mundo. Agostinho sabe disso e, se está falando sobre o ideal de amor a Deus e ao próximo é porque enxergou nesse ideal, não apenas virtudes morais da religião cristã, mas principalmente uma "experiência humana" muito profunda e autêntica, uma "atitude de vida" capaz de transformar positivamente a realidade pessoal e social em que vivemos.

Quando concorda que o amor de Deus se difundiu no coração do ser humano, por que o próprio Deus tomou a iniciativa de fazer isso $(\mathrm{Rm}$ $5,5)$, santo Agostinho está indicando um caminho de transformação pessoal e coletiva. Um caminho que ele mesmo encontrou e seguiu. Trata-se de uma experiência espiritual que possui profundas consequências políticas, sociais e culturais. Constitui-se num "novo olhar" e também numa "nova atitude" bem concreta, diante das situações humanas. Sim, o ser humano pode ser proativo e empenhar-se no enfrentamento do mal que há no mundo, por uma razão simultaneamente simples e profunda: o ser humano não está sozinho nessa luta. Deus mesmo o acompanha, de um modo muito íntimo e pessoal, inspirando, convidando ao discernimento, motivando à ação...amando o ser humano e provocando-o a também amar.

A experiência dessa descoberta pessoal vivida por Agostinho foi, de certo, amparada também pelo exemplo do próprio Jesus Cristo que lutou até a morte, procurando aliviar os sofrimentos das pessoas, perdoando pecadores, curando doentes, acolhendo sem reservas os mais pobres e anunciando-lhes uma esperança de vida, por entender que era este o projeto ("o Reino") de Deus. Ao contemplar e sentir tudo isso de um modo singular e pessoal, Agostinho adquiriu uma força interior inabalável que o transformou num "agente de transformação".

Sua convicção íntima de que o amor é uma força poderosa, que provem de Deus mesmo e reconfigura nossa existência foi tão forte, que o levou confiar plenamente nesta experiência de fé e nesta nova atitude de vida. Um famoso comentário escrito por Agostinho registra essa experiência de forma admirável.

"Uma vez por todas, foi-te dado somente um breve mandamento: AMA E FAZE O QUE QUISERES. Se te calas, cala-te movido pelo amor; se falas em tom alto, fala por amor; se corriges, corrige com amor; se perdoas, perdoa com amor. Tem 
no fundo do coração a raiz do amor: dessa raiz não pode sair senão o bem!" 7

\section{Conclusão}

Diante de tudo isso, há razões suficientes para acreditar que somos livres? Mesmo considerando o gravíssimo problema do mal, que tolhe e restringe tanto a nossa capacidade de compreender a vida e agir no mundo, podemos ainda acreditar na liberdade? A partir das observações apresentadas por Agostinho, a resposta parece mesmo ser afirmativa.

É verdade que muitos contextos econômicos e sociais constituem grandes tragédias humanas, impondo severos limites à vida das pessoas. No entanto, é igualmente verdadeiro que o ser humano tem apresentado ao longo da história grande variedade de iniciativas, projetos, descobertas científicas, atitudes pessoais e sociais no embate contra 0 mal.

Na perspectiva da fé , vivida e defendida por Agostinho, a busca de superação do mal é um sinal de esperança. É uma prova de que a liberdade de fato existe. A capacidade de reflexão e ação do ser humano é uma dádiva de Deus num duplo sentido. É um dom natural, porque todos nascemos com potencialidades a serem desenvolvidas. Nossa capacidade de aprender, raciocinar, pesquisar, adquirir cultura, ter fé, agir, lutar contra o sofrimento... tudo isso faz parte de nossa vida como seres humanos. É uma capacidade humana que evolui. Em segundo lugar a liberdade é um dom de Deus no sentido de que ela nos é dada, a fim de que possamos ser felizes, a fim de que possamos aprender a viver uma vida com potencialidade para "ser mais", "viver mais", se "aperfeiçoar mais". E mais ainda: como a experiência pessoal e a fé cristã de Agostinho nos mostram, a liberdade humana é uma dádiva divina porque é também um "projeto de vida" desenvolvido e sustentado pela ação amorosa de Deus. Trata-se de uma liberdade que pode e deve ser vivenciada no amor e por amor.

Poderemos considerar que tudo isso não fará o mal desaparecer instantaneamente da existência humana. No entanto, a liberdade vai

\footnotetext{
${ }^{7}$ Santo Agostinho, Comentário da primeira Epístola de São João 7,8. Fizemos o destaque com letras maiúsculas, a fim de enfatizar a importância do tema em nossa reflexão sobre a liberdade.
} 
abrindo caminho, fazendo descobertas, apontando rumos, fazendo avançar a vida humana, tanto no seu sentido pessoal como no seu sentido social. Ouvindo e aprendendo da reflexão proposta por santo Agostinho, podemos compreender a vida humana como um exercício constante de aprender a construir e redimir a nossa própria existência neste mundo. Viver é assumir esse caminho de liberdade, mesmo com seus percalços. Como vimos é sim possível trilhar esse caminho com esperança. E pensando bem, há bons motivos para fazê-lo.

Bibliografia

QUEIRUGA A. T., Um Deus para hoje, São Paulo: Paulus, 1998.

Santo Agostinho, Comentário da primeira epístola de São João, São Paulo: Paulinas, 1989.

O Espírito e a Letra, em A Graça (I) / Santo Agostinho, São Paulo: Paulus, 1998.

O livre arbítrio, São Paulo: Paulus, 1995.

Comentário aos Salmos, São Paulo: Paulus, 2008.

Confissões, São Paulo: Paulus, 1997. 